\title{
Regular exercise might be associated with higher skeletal muscle volume, favorable prognostic factor in breast cancer patients
}

\author{
Kadri Altundag ${ }^{1}$ (D)
}

Received: 25 August 2018 / Accepted: 31 August 2018 / Published online: 3 September 2018

○) Springer Science+Business Media, LLC, part of Springer Nature 2018

\section{Dear Editor,}

I want to congratulate Song and their colleagues for their article [1] in which they investigated whether the prognosis of breast cancer is affected by muscle or fat volume as measured from computed tomography (CT) images. They concluded that breast cancer patients with higher skeletal muscle volume showed more favorable prognosis. The authors did not give detailed information about exercise data for these patients. Exercise is associated with significant reductions in the recurrence and mortality rates of several common cancers including breast cancer. Exercise during and following treatment has been associated with reductions in breast cancer recurrence and disease-specific mortality rates of 30-60\% [2]. Additionally, regular exercise by itself increases skeletal muscle volume in the body [3]. Since skeletal muscle volume data were measured from chest CT scan performed within first 2-years of breast cancer diagnosis in the current study, it might reflect somehow which patients really did exercise during this period. Taken all together, regular exercise might be associated with higher skeletal

Kadri Altundag

altundag66@yahoo.com

1 MKA Breast Cancer Clinic, Tepe Prime, Cankaya, 06800 Ankara, Turkey muscle volume, favorable prognostic factor in breast cancer patients. This issue merits further investigation.

\section{Compliance with ethical standards}

Conflict of interest I have no conflict of interest to declare.

Human and animal rights This article does not contain any studies with human participants or animals performed by any of the authors.

\section{References}

1. Song EJ, Lee CW, Jung SY et al. (2018) Prognostic impact of skeletal muscle volume derived from cross-sectional computed tomography images in breast cancer. Breast Cancer Res Treat. https://doi.org/10.1007/s10549-018-4915-7

2. Irwin ML, McTiernan A, Manson JE et al (2011) Physical activity and survival in postmenopausal women with breast cancer: results from the Women's Health Initiative. Cancer Prev Res (Phila) 4(4):522-529

3. Kida K, Osada N, Akashi YJ, Sekizuka H, Omiya K, Miyake F (2008) The exercise training effects of skeletal muscle strength and muscle volume to improve functional capacity in patients with myocardial infarction. Int J Cardiol 129(2):180-186 